RESEARCH

Turkish Journal of Geriatrics

DOI: 10.31086/tigeri.2020.174

2020; 23(3): 374-383

- Yelda SOLUK ÖZDEMIR' ${ }^{1}$ D

- Nurdan PAKER' (D)

CORRESPONDANCE

Yelda SOLUK ÖZDEMIR

İstanbul Physical Medicine and Rehabilitation

Training and Research Hospital, Physical

Medicine and Rehabilitation, İstanbul, Turkey

Phone: +902124965000

e-mail: yeldasoluk@hotmail.com

Received: Jun 01, 2020

Accepted: Aug 05, 2020

\section{THE RELATIONSHIP BETWEEN EMOTIONAL STATE AND QUALITY OF LIFE OF FAMILY CAREGIVERS OF STROKE PATIENTS AND PATIENT FACTORS}

\section{Abstract}

Introduction: We aimed to evaluate the emotional state and quality of life of family caregivers of stroke patients and to investigate the relationship between patient factors and these characteristics of caregivers.

Materials and Method: Ninety-seven patients with hemiplegia after a cerebrovascular event and their caregivers were included in this cross-sectional study. The emotional state of the caregivers was evaluated with the Hospital Anxiety and Depression Scale (HADS). Their quality of life was evaluated with Short Form36. Functional Independence Measurement (FIM) and modified-Rankin Score (MRS) were used for functional status of the patients, HADS was used for their emotional state and Stroke-Specific Quality of Life Scale (SS-QOL) was used for their quality of life.

Results: Mean HADS-Anxiety score was $9.0 \pm 3.7$ and mean HADS-Depression score was $8.3 \pm 3.7$ in caregivers. Mean HADS-Anxiety score was $10.1 \pm 3.4$ and mean HADS-D score was $8.7 \pm 3.6$ in patients. The rates of anxiety disorder and depression in caregivers were $39.2 \%$ and $55.7 \%$, respectively. The rates of anxiety disorder and depression in stroke patients were $40.2 \%$ and $50.5 \%$, respectively. A positive correlation was found between HADS scores of caregivers and patients $(p<0.05)$. There was a significant negative correlation between the HADS scores of caregivers and SS-QOL scores of patients $(p<0.05)$. There was a statistically significant relationship between the quality of life of caregivers and the MRS, motor FIM and FIM-total scores of patients $(\mathrm{p}<0.05)$.

Conclusion: As a result, mood disorders were common in stroke patients and their caregivers. Quality of life of caregivers was decreased. There was a relationship between the emotional state of patients and caregivers.

Keywords: Stroke; Caregivers; Anxiety; Depression; Quality of life
İstanbul Physical Medicine and Rehabilitation Training and Research Hospital, Physical Medicine and Rehabilitation, İstanbul, Turkey 


\section{INTRODUCTION}

Stroke is one of the most frequent causes of death in the world, affecting the elderly population in particular, which may result in significant functional disability and has a high socio-economic social burden. With increasing life expectancy, the problems caused by stroke have begun to increase too. A significant proportion of patients loses functional independence and requires continuous or temporary care following a stroke. Provided the unexpected and sudden nature of stroke, it is logical to assume that families are caught unprepared for adapting to the role of caregiver.

The role of caregivers in the treatment of diseases characterised by chronic and functional disability is greater than in other diseases. The caregiver, who is the person who lives with the patient and is most engaged in the care of the patient, is exposed to stress caused by physical, social, psychological and financial factors of the patient, their own, or the environment (1). Although caregiver burden varies according to the factors of the patient and caregiver, it is significantly effective in 25-54\% of stroke caregivers (2). Factors considered to be related to caregiver burden are characteristics such as the severity of neurological deficits, functional and emotional state of patients, emotional state of caregivers, health status, duration of care and social support (3). Patient care may cause significant stress burden in caregivers and result in changes in mood. The increase in care burden is associated with the frequency of anxiety and depression in the caregiver (4). Better understanding of caregiver burden will also have positive consequences for patients.

Although many studies have focused on the incidence and prevalence of stroke, the number of studies on the effects of stroke on caregivers and its long-term outcomes is limited. Clarification of factors associated with both patients and caregivers that may affect caregiver burden will provide a better understanding of caregiver burden after stroke and help reduce the financial and emotional burden of patient care. Caregiver burden was frequently examined in previous studies, and subsequent studies focused on factors that had an impact on caregiver burden. It was noted that the quality of life of the caregiver decreased in cases where caregiver burden was high (5).

Therefore, we aimed to evaluate the emotional state and quality of life of family caregivers of stroke patients, and to investigate the relationship between patient factors and these characteristics of caregivers.

\section{MATERIALS AND METHOD}

Ninety-seven patients with hemiplegia due to vascular stroke who were admitted to a tertiary rehabilitation hospital between 1 January 2017 and 30 June 2017 and their family caregivers were included in this cross-sectional study. This crosssectional study was approved by the research ethics committee with the number of 2017/217.

Stroke patients who had ischaemic or haemorrhagic stroke at least 3 months ago included in the study. Patients with traumatic or tumourrelated stroke, bilateral stroke, multiple stroke, aphasia and severe communication disorder, or other neurological disorders that could affect cognitive functions such as multiple sclerosis or Parkinson's disease, and a stroke duration of $>24$ months were excluded from the study. Inclusion criteria for caregivers were a caregiving duration of $\geq 3$ months, family members and a mini mental state examination score of $>24$. The exclusion criteria for caregivers were professional caregivers, non-family members, caregivers with comorbid psychiatric disorders, or those who had previously given care for at least 1 month in the last two years.

Hospital Anxiety Depression Scale (HADS) was used for assessing the emotional state of the caregivers and Short Form-36 (SF-36) was used 
for assessing their quality of life. Modified-Rankin scale and Functional Independence Measurement (FIM) were used for evaluating functional status, HADS was used for evaluating emotional state, and Stroke-Specific Quality of Life Scale (SS-QLS) was used for evaluating the quality of life of the patients.

\section{Functional Independence Measurement (FIM)}

FIM shows the level of independence of the individual in daily life activities (6). It consists of 18 items including self-care, sphincter control, transfer, movement, communication, social perception and cognitive status. The total score is between 18 and 126. Motor sub-dimension consists of 13 items and cognitive sub-dimension consists of 5 items. High FIM scores indicate a high level of independence. The Turkish validity and reliability study was conducted by Küçükdeveci et al. (7).

\section{Modified-Rankin Score (MRS)}

MRS is a widely used scale for expressing functional outcomes in stroke-related conditions. It is a seven-level categorical scale. In MRS, a score of 0 indicates full independence, whereas a score of 5 indicates very severe disability and 6 indicates death.

\section{Stroke-Specific Quality of Life Scale (SS-QLS)}

SS-QLS is a disease-specific quality of life scale and consists of 49 items that assess 12 domains: social role (5 items), mobility (6 items), energy (3 items), language ( 5 items), self-care (5 items), mood (5 items), personality (3 items), thinking (3 items), upper extremity function ( 5 items), family roles (3 items), vision (3 items), and work/productivity (3 items). The scores of these 12 domains are summed to obtain a total score of 49-245. Higher scores indicate a better quality of life (8).

\section{Short form-36 (SF-36)}

SF-36 is the most frequently used method for evaluating the quality of life of an individual (9).
It is a self-report scale and consists of 36 items and 9 subscales: physical function, physical role, emotional role, vitality/energy, mental health, social function, pain, general health and change in health. Higher scores indicate a better quality of life. The Turkish validity and reliability study was conducted (10).

\section{Hospital Anxiety and Depression Scale (HADS)}

It was developed in 1983 by Zigmond and Snaith to determine and evaluate the anxiety and depression risks of patients (11). The scale consists of 14 items in total. It consists of the subscales of depression and anxiety that consist of seven items each. Each scale is scored between 0 and 21. Higher scores indicate higher disease severity. Turkish validity and reliability study of this scale was conducted (12). Cut-off values used in previous studies were $\geq 8$ for anxiety and $\geq 8-11$ for depression scale (13). A cut-off value of 8 was used for depression.

\section{Statistical analysis}

Statistical analyses were performed using SPSS version 20.0 package program. Descriptive statistics were summarised as number, percentage, mean \pm standard deviation, and median. The normality of the distribution of variables was examined using visual (histogram and probability graphs) and analytical methods (Shapiro-Wilk test). Numerical variables determined according to whether they were normally distributed were compared between two groups using independent samples $t$ test and between three groups using one-way ANOVA test. Pearson and Spearman correlation tests were used in correlation analyses. A correlation coefficient of $0.05-0.30$ was accepted as low or insignificant correlation, $0.30-0.40$ as poor-moderate correlation, $0.40-0.60$ as moderate correlation, $0.60-0.70$ as strong correlation, 0.70 0.75 as very strong correlation, and $0.75-1.00$ as perfect correlation. The homogeneity of the variances was evaluated by Levene test. In cases 
Table 1. Demographic and clinical characteristics of stroke patients and their family caregivers

\begin{tabular}{|c|c|c|c|c|c|c|c|c|c|}
\hline \multirow{3}{*}{\multicolumn{2}{|c|}{\begin{tabular}{|l} 
\\
Age (years) \\
\end{tabular}}} & \multicolumn{4}{|c|}{ Family caregivers } & \multicolumn{4}{|c|}{ Stroke patients } \\
\hline & & \multirow{2}{*}{\begin{tabular}{|l|} 
Min-Max \\
$25-75$ \\
\end{tabular}} & \multirow{2}{*}{$\begin{array}{l}\text { Median } \\
52\end{array}$} & Mean \pm SD & \multirow{2}{*}{$\begin{array}{l}/ \mathrm{n} \% \\
13\end{array}$} & \multirow{2}{*}{\begin{tabular}{|l} 
Min-Max \\
$30-83$
\end{tabular}} & \multirow{2}{*}{$\begin{array}{l}\text { Median } \\
62\end{array}$} & \multicolumn{2}{|c|}{ Mean \pm SD / $n \%$} \\
\hline & & & & $49.9 \pm$ & & & & $60.0 \pm$ & 12.4 \\
\hline \multirow{2}{*}{ Gender } & Female & & & 73 & 75.3 & & & 51 & 52.6 \\
\hline & Male & & & 24 & 24.7 & & & 46 & 47.4 \\
\hline \multirow{3}{*}{$\begin{array}{l}\text { Marital } \\
\text { Status }\end{array}$} & Married & & & 64 & 66 & & & 72 & 74.2 \\
\hline & Single & & & 27 & 27.8 & & & 7 & 7.2 \\
\hline & Widowed & & & 6 & 6.2 & & & 18 & 18.6 \\
\hline \multirow{5}{*}{ Education } & Illiterate & & & 10 & 10.3 & & & 19 & 19.6 \\
\hline & Primary school & & & 43 & 44.3 & & & 42 & 43.3 \\
\hline & Middle school & & & 9 & 9.3 & & & 12 & 12.4 \\
\hline & High school & & & 29 & 29.9 & & & 13 & 13.4 \\
\hline & University & & & 6 & 6.2 & & & 11 & 11.3 \\
\hline \multirow{4}{*}{ Occupation } & Housewife & & & 65 & 67 & & & 47 & 48.4 \\
\hline & Occupation & & & 23 & 23.7 & & & 22 & 22.7 \\
\hline & Worker & & & 7 & 7.2 & & & 15 & 15.5 \\
\hline & Civil servant & & & 2 & 2.1 & & & 13 & 13.4 \\
\hline \multicolumn{2}{|c|}{ Duration of Care (Months) } & 3-14 & 5 & $6.6 \pm$ & 2.9 & & & & \\
\hline \multicolumn{2}{|c|}{ Disease Duration (Months) } & & & & & $4-16$ & 7 & $7.5 \pm$ & 3.2 \\
\hline \multirow{2}{*}{$\begin{array}{l}\text { Stroke } \\
\text { Aetiology }\end{array}$} & Ischaemic & & & & & & & 73 & 75.3 \\
\hline & Haemorrhagic & & & & & & & 24 & 24.7 \\
\hline \multirow{2}{*}{ Stroke Side } & Right & & & & & & & 38 & 39.2 \\
\hline & Left & & & & & & & 59 & 60.8 \\
\hline \multirow{2}{*}{$\begin{array}{l}\text { Dominant } \\
\text { Hand }\end{array}$} & Right & & & & & & & 85 & 87.6 \\
\hline & Left & & & & & & & 12 & 12.4 \\
\hline
\end{tabular}

with significant differences, post-hoc analyses were performed with Tukey and Bonferonni tests. Numerical variables that did not show normal distribution were compared between two groups using Mann Whitney $U$ test and between three and more groups using Kruskal-Wallis Test. Nominal data were evaluated between two groups using Chi-square test. $\mathrm{P}$ values less than 0.05 were considered statistically significant in all statistical analyses conducted for the study.

\section{RESULTS}

The demographic and clinical characteristics of the caregivers and stroke patients are summarised in Table 1. All caregivers were family members, 
including their spouse $(48.5 \% \mathrm{n}=47)$, children (37.1\%, $n=36)$, brother/sister $(10.3 \%, n=10)$ and parents $(4.1 \%, n=4)$.

The mean HADS-A score of the caregivers was $9.0 \pm 3.7$ (median 9, range 2-17), and the mean HADS-D score was $8.3 \pm 3.7$ (median 8 , range 2-20) (Table 2). Of the caregivers, 39.2\% $(n=38)$ had anxiety disorder (HADS-A $\geq 11$ ) and $55.7 \%$ ( $=54$ ) had depression (HADS-D $\geq 8$ ). The individual SF-36 subscale scores of caregivers are given in Table 2.

The mean MRS score of stroke patients was 3.3 \pm 0.8 (median 3, range 2-5), the mean FIM-motor score was $53.8 \pm 15.7$ (median 55, range 24-84), the mean FIM-cognitive score was $30.2 \pm 2.9$ (median 30 , range 25-46), mean FIM-total score was 84.0 \pm 17.3 (median 86, range 50-119), mean HADS-A score was $10.1 \pm 3.4$ (median 9, range 3-18), and mean HADS-D score was $8.7 \pm 3.6$ (median 8, range 2-19) (Table 3).

A total of $40.2 \%$ ( $n=39$ ) of the patients had anxiety disorder (HADS-A $\geq 11)$ and $50.5 \%(n=49)$ had depression (HADS-D $\geq 8$ ). The mean SSOLS score of the patients was $144 \pm 26$ (median 149, range 92-196). The individual scores of the 12 domains assessed using SSOLS are given in Table 3.

A positive correlation was found between the HADS-A score of the caregivers and HADS-A ( $p$ $=0.015)$ and HADS-D $(p=0.037)$ scores of the patients. There was a positive correlation between the HADS-D score of the caregivers and HADS-A $(p=0.028)$ and HADS-D $(p=0.022)$ scores of the patients (Table 4).

There was a negative correlation between the HADS-A scores ( $p=0.037)$ and HADS-D scores ( $p$ $=0.040$ ) of the caregivers and SS-QLS scores of the patients (Table 4).

A positive correlation as noted between duration of care and HADS-A $(p=0.041)$ and HADS-D $(p=0.014)$ scores of the caregivers. There was a positive correlation between the age of caregivers and HADS-A score $(p=0.007)$. However, no correlation was noted between age

Table 2. HADS-A and HADS-D scores and SF-36 subscale scores of family caregivers

\begin{tabular}{|c|c|c|c|}
\hline \multicolumn{4}{|l|}{ Family caregivers } \\
\hline & Min-Max & Median & Mean \pm SD \\
\hline HADS-A & $2-17$ & 9 & $9.0 \pm 3.7$ \\
\hline HADS-D & $2-20$ & 8 & $8.3 \pm 3.7$ \\
\hline \multicolumn{4}{|l|}{ SF-36 subscale scores: } \\
\hline Physical function & $35-100$ & 80 & $78 \pm 12$ \\
\hline Physical role & $0-100$ & 50 & $53 \pm 25$ \\
\hline Emotional role & $0-100$ & 33 & $45 \pm 30$ \\
\hline Vitality/energy & $15-95$ & 45 & $49 \pm 19$ \\
\hline Mental health & 24-88 & 56 & $58 \pm 13$ \\
\hline Social function & $0-100$ & 50 & $50 \pm 18$ \\
\hline Pain & $10-100$ & 45 & $49 \pm 24$ \\
\hline Overall health status & $30-90$ & 65 & $62 \pm 15$ \\
\hline Change in health & $0-75$ & 50 & $42 \pm 16$ \\
\hline
\end{tabular}


Table 3. HADS-A and HADS-D scores, FIM scores, MRS score and SS-QLS scores of stroke patients

\begin{tabular}{|c|c|c|c|}
\hline \multicolumn{4}{|l|}{ Stroke patients } \\
\hline & Min-Max & Median & Mean \pm SD \\
\hline HADS-A & $3-18$ & 9 & $10.1 \pm 3.4$ \\
\hline HADS-D & $2-19$ & 8 & $8.7 \pm 3.6$ \\
\hline FIM-motor score & $24-84$ & 55 & $53.8 \pm 15.7$ \\
\hline FIM-cognitive score & $25-46$ & 30 & $30.2 \pm 2.9$ \\
\hline FIM-total score & $50-119$ & 86 & $84.0 \pm 17.3$ \\
\hline MRS score & $2-5$ & 3 & $3.3 \pm 0.8$ \\
\hline \multicolumn{4}{|l|}{ SF-36 subscale scores: } \\
\hline Energy & $3-13$ & 8 & $7.7 \pm 2.6$ \\
\hline Family roles & $3-12$ & 8 & $7.4 \pm 2.1$ \\
\hline Language & $14-25$ & 22 & $21.0 \pm 3.2$ \\
\hline Mobility & $6-25$ & 17 & $15.5 \pm 5.9$ \\
\hline Mood & $7-25$ & 15 & $14.0 \pm 3.8$ \\
\hline Personality & $3-14$ & 8 & $8.4 \pm 2.2$ \\
\hline Self-care & $6-21$ & 12 & $12.3 \pm 3.4$ \\
\hline Social roles & $6-20$ & 13 & $13.0 \pm 2.9$ \\
\hline Thinking & $7-15$ & 11 & $11.4 \pm 1.9$ \\
\hline Upper extremity function & $6-23$ & 14 & $13.3 \pm 3.9$ \\
\hline Vision & $9-25$ & 14 & $13.8 \pm 1.4$ \\
\hline Work/Productivity & $3-11$ & 6 & $6.0 \pm 2.3$ \\
\hline
\end{tabular}

and HADS-D score $(p=0.245)$. There was no correlation between HADS-A and HADS-D scores of caregivers and FIM scores of patients ( $p>0.05)$ (Table 4).

A negative correlation was noted between physical role $(p=0.045)$ and emotional role ( $p$ $=0.017$ ) subscales and HADS-A scores of the caregivers. No correlation was noted between SF-36 subscale scores of caregivers and HADS-D scores of patients. A positive correlation was noted between caregivers' emotional role subscale scores $(p=0.036)$ and SS-QLS scores of the patients (Table 5).

A negative correlation was noted between duration of care given by caregivers and physical role $(p=0.018)$, social function $(p=0.040)$ and change in health ( $p=0.026)$ subscale scores of the caregivers. A negative correlation was noted between caregiver age and physical function $(p<$ $0.001)$, physical role $(p<0.001)$, emotional role ( $p$ $=0.026)$, vitality/energy $(p=0.014)$, social function $(p=0.020)$, pain $(p=0.001)$ and overall health $(p=$ 0.005) (Table 5).

A positive correlation was noted between the physical role subscale scores of caregivers and motor FIM scores of the patients $(p=0.038)$. A positive correlation was noted between physical role subscale scores of caregivers and FIM-total scores of the patients ( $p=0.039$ ) (Table 5).

\section{DISCUSSION}

In the present study, $40.2 \%$ of stroke patients had 
Table 4. The effect of patient variables on HADS-A and HADS-D scores of caregivers

\begin{tabular}{|l|l|l|l|}
\hline & CAREGIVER & \\
\hline \multirow{2}{*}{ PATIENT } & HADS-A* & HADS-A & HADS-D \\
\cline { 2 - 4 } & HADS-D* & $R=0.221, p=0.015$ & $R=0.223, p=0.028$ \\
\cline { 2 - 4 } & SSQLS** & $R=0.299, p=0.037$ & $R=0.158, p=0.022$ \\
\hline & Modified Rankin scale* & $R h o=-0.181, p=0.037$ & $R h o=-0.200, p=0.040$ \\
\hline & Duration of care* & $R=0.081, p=0.431$ & $R=0.086, p=0.402$ \\
\hline & Age of caregiver & $R=0.208, p=0.041$ & $R=0.250, p=0.014$ \\
\hline & FIM-Motor & $R=0.273, p=0.007$ & $R=0.119, p=0.245$ \\
\hline & FIM-Cognitive* & $R=-0.103, p=0.316$ & $R=-0.131, p=0.200$ \\
\hline & FIM-Total* & $R=-0.044, p=0.670$ & $R=-0.029, p=0.775$ \\
\hline
\end{tabular}

* Pearson correlation analysis, $r=$ correlation coefficient, rho $=$ correlation coefficient

**Spearman correlation coefficient

anxiety disorder and $50.5 \%$ had depression. Anxiety disorder was found in $39.2 \%$ and depression was found in $55.7 \%$ of the caregivers. In previous studies, anxiety and depression rates in caregivers of stroke patients have been reported as $21 \%-56 \%$ and $18 \%-52 \%$, respectively $(4,14-17)$. Depression and anxiety rates in caregivers of stroke patients in the present study were similar to the results of previous studies.

An important finding of this study was that the depression and anxiety levels of stroke caregivers had a markedly positive correlation with emotional state of the patients. In contrast, another study indicated that there was no significant correlation between anxiety and depression levels of patients and their caregivers (14).

In the present study, a positive correlation was found between the anxiety and depression levels of caregivers and duration of care. In addition, a positive correlation was noted between anxiety level and age of the caregiver, but no correlation was noted between the age and depression level of caregiver. In the present study, no correlation was noted between anxiety and depression levels of caregivers and functional independence levels of patients.

In a previous study, factors increasing the burden of caregivers were reported to be duration of patient care, social support, depressive symptoms of patients, neurological and functional status of patients, high emotional stress, and poor functional status of patients (3). In the study by Epstein-Lubow et al. (15), it was found that the factors affecting the high frequency of depression in caregivers of stroke patients were female gender and low educational level of the caregiver, male gender and high stroke severity of the patient, and poor overall health of the caregiver.

In the present study, it was found that the quality of life of caregivers of stroke patients was 
negatively affected. Similarly, in previous studies, the quality of life of caregivers of stroke patients has been suggested to decrease (18-20).

In the present study, nearly all subscales of caregiver quality of life measured by SF-36 were found to be negatively correlated with caregiver age. Emotional role subscales of caregivers were found to be correlated with quality of life of patients ( $p=0.036$ ). In addition, there was a negative correlation between emotional state of caregivers and quality of life of patients. Similar to our results, McPherson et al. reported that the quality of life of caregivers was lower than that of the general population and that all SF-36 subscales were correlated with the quality of life of stroke patients measured by SS-QLS (20). In a previous study, it was reported that age of the caregiver and functional status of the patients were crucial determinants of the quality of life of stroke caregivers (21).

In the present study, the quality of life of the caregivers was correlated with functional status and functional independence level of the patients measured by the Modified Rankin scale score, motor FIM and FIM total. In a previous study, it was reported that caregiver burden and quality of life were negatively correlated in caregivers of stroke patients, and the decrease in the quality of

Table 5. The relationship between patient variables and SF-36 scores of caregivers

\begin{tabular}{|c|c|c|c|c|c|c|c|c|c|c|}
\hline & & $\begin{array}{l}\text { Physical } \\
\text { function }\end{array}$ & $\begin{array}{l}\text { Physical } \\
\text { role }\end{array}$ & $\begin{array}{l}\text { Emotional } \\
\text { role }\end{array}$ & $\begin{array}{l}\text { Vitality } \\
\text { Energy }\end{array}$ & $\begin{array}{l}\text { Mental } \\
\text { health }\end{array}$ & $\begin{array}{l}\text { Social } \\
\text { function }\end{array}$ & Pain & $\begin{array}{l}\text { Overall } \\
\text { health }\end{array}$ & $\begin{array}{l}\text { Change } \\
\text { in } \\
\text { health }\end{array}$ \\
\hline \multirow{2}{*}{ HADS-A } & $R$ & 0.063 & -0.204 & -0.242 & -0.093 & -0.146 & -0.182 & -0.104 & 0.024 & -0.024 \\
\hline & $\mathrm{p}$ & 0.542 & 0.045 & 0.017 & 0.363 & 0.155 & 0.074 & 0.309 & 0.813 & 0.819 \\
\hline \multirow{2}{*}{ HADS-D } & $\mathrm{R}$ & 0.113 & -0.136 & -0.188 & -0.061 & -0.058 & -0.153 & -0.045 & 0.133 & 0.026 \\
\hline & $\mathrm{p}$ & 0.272 & 0.185 & 0.066 & 0.553 & 0.574 & 0.134 & 0.664 & 0.194 & 0.802 \\
\hline \multirow{2}{*}{ SSOLS } & $\mathrm{R}$ & -0.106 & 0.198 & 0.213 & 0.061 & 0.116 & 0.155 & 0.107 & 0.028 & 0.159 \\
\hline & $p$ & 0.301 & 0.052 & 0.036 & 0.555 & 0.257 & 0.131 & 0.295 & 0.785 & 0.120 \\
\hline \multirow{2}{*}{$\begin{array}{l}\text { Modified Rankin } \\
\text { scale }\end{array}$} & $R$ & 0.129 & -0.210 & -0.232 & -0.041 & -0.094 & -0.150 & -0.056 & 0.019 & -0.102 \\
\hline & $p$ & 0.207 & 0.039 & 0.022 & 0.688 & 0.359 & 0.142 & 0.589 & 0.851 & 0.321 \\
\hline \multirow{2}{*}{$\begin{array}{l}\text { Duration of } \\
\text { care }\end{array}$} & $R$ & -0.199 & -0.240 & -0.068 & -0.193 & -0.077 & -0.209 & -0.080 & -0.185 & -0.226 \\
\hline & $p$ & 0.051 & 0.018 & 0.508 & 0.058 & 0.454 & 0.040 & 0.434 & 0.069 & 0.026 \\
\hline \multirow{2}{*}{$\begin{array}{l}\text { Age of } \\
\text { caregiver }\end{array}$} & $R$ & -0.528 & -0.429 & -0.226 & -0.250 & -0.112 & -0.236 & -0.336 & -0.285 & -0.034 \\
\hline & $p$ & $<0.001$ & $<0.001$ & 0.026 & 0.014 & 0.274 & 0.020 & 0.001 & 0.005 & 0.740 \\
\hline \multirow{2}{*}{ FIM-Motor } & $R$ & -0.126 & 0.211 & 0.198 & 0.049 & 0.080 & 0.142 & 0.059 & -0.017 & 0.095 \\
\hline & $p$ & 0.219 & 0.038 & 0.052 & 0.636 & 0.438 & 0.165 & 0.565 & 0.867 & 0.354 \\
\hline \multirow{2}{*}{ FIM-Cognitive } & $R$ & -0.185 & 0.111 & 0.026 & 0.002 & 0.032 & 0.094 & 0.084 & 0.026 & 0.124 \\
\hline & $p$ & 0.069 & 0.279 & 0.803 & 0.988 & 0.759 & 0.358 & 0.413 & 0.803 & 0.225 \\
\hline \multirow{2}{*}{ FIM-Total } & $R$ & -0.145 & 0.210 & 0.184 & 0.044 & 0.077 & 0.145 & 0.068 & -0.011 & 0.107 \\
\hline & $p$ & 0.155 & 0.039 & 0.072 & 0.667 & 0.451 & 0.158 & 0.509 & 0.913 & 0.296 \\
\hline
\end{tabular}

* Pearson correlation test, $r=$ correlation coefficient 
life of caregivers was associated with the decrease in functional status of the patients evaluated with MRS and Barthel index (22). Another one has shown an inverse relationship between care burden and quality of life of caregivers (23).

In the present study, no correlation was noted between depression scores of patients and quality of life of their caregivers. Anxiety levels of the patients were found to be correlated with physical role and emotional role subdomains of quality of life of caregivers. In the study of Pinedo et al., it was reported that the quality of life of both patients and caregivers decreased, and similar to the results of the present study, the presence of depression in patients did not have a significant effect on the quality of life of caregivers (24).

There are certain strengths and limitations of the present study. The first strength of this study is that all evaluations were made face to face. The second strength is that Turkish validity and reliability studies were previously performed for all the scales used. The first limitation is that the cause-effect relationship could not be evaluated due to the cross-sectional design of the study.

\section{REFERENCES}

1. Zarit S, Reever K, Bach-Peterson J. Relatives of the impaired elderly: Correlates of feelings of burden. Gerontologist 1980;20(6):649-55. (PMID:7203086).

2. Rigby H, Gubits G, Philips S. A systematic review of caregiver burden following stroke. Int J Stroke 2009;4(4):285-92. (PMID:19689757).

3. Jaracz K, Grabowska-Fudala B, Kozubski W. Caregiver burden after stroke: towards a structural model. Neurol Neurochir Pol 2012;46(3):224-32. (PMID:22773508).

4. Denno M, Gillard P, Graham G, et al. Anxiety and depression associated with caregiver burden in caregivers of stroke survivors with spasticity. Arch Phys Med Rehabil 2013;94(9):1731-6. (PMID:23548544).
Another limitation was the inclusion of patients and caregivers in the stroke rehabilitation unit in the study. Therefore, our findings included patients with clinically more severe neurological deficits. The results obtained may therefore not be generalisable to all stroke patients.

In conclusion, it was found that mood disorders occurred frequently in stroke patients and their family caregivers, and there was a correlation between the emotional states of patients and caregivers. In addition, the quality of life of caregivers decreased. Therefore, treatment of diseases that limit the functional independence of patients and require active involvement of caregivers such as stroke should not be conducted from just a patient-oriented perspective, but rather from a patient-caregiver-oriented perspective. Monitoring and paying attention to caregivers who have increased anxiety and depressive symptoms and decreased quality of life in the treatment and rehabilitation process will make a significant contribution towards better patient outcomes.

\section{Conflict of Interest}

No conflict of interest to disclosure.

5. Godwin K, Ostwald S, Cron S, Wasserman J. Longterm health related quality of life of survivors of stroke and their spousal caregivers. J Neurosci Nurs 2013;45(3):147-54. (PMID:23558977).

6. Granger C, Hamilton B, Keith RA, Zielezny M, Frances SS. Advances in functional assessment in medical rehabilitation. Top Geriatr Rehabil 1986;1:59-74.

7. Küçükdeveci A, Yavuzer G, Elhan A, Sonel B, Tennant BA. Adaptation of the functional independence measure for use in Turkey. Clin Rehabil 2000;15(3):31119. (PMID:11386402).

8. Mahmoodi M, Safari A, Vossoughi M, et al. Stroke specific quality of life questionnaire: Test of reliability and validity of the Persian version. Iran J Neurol 2015;14(2):94-100. (PMID:26056554). 
9. Lahmek P, Berlin I, Michel L, et al. Determinants of improvement in quality of life of alcohol-dependent patients during an inpatient withdrawal programme. Int J Med Sci 2009;6(4):160-67. (PMID:19461935).

10. Pinar R. Reliability and construct validity of the SF-36 in Turkish cancer patients. Qual Life Res 2005;14(1):25964. (PMID:15789959).

11. Zigmond A, Snaith R. The hospital anxiety and depression scale. Acta Psychiatr Scand 1983;67(6):36170. (PMID:6880820).

12. Paker N, Bugdayci D, Midik M, Celik B, Kesiktas N. Reliability of the Turkish version of the Hospital Anxiety and Depression Scale in the people with traumatic spinal cord injury. NeuroRehabilitation 2013;33(2):337-41. (PMID:23949046).

13. Bjelland I, Dahl A, Haug T, Neckelmann D. The validity of the hospital anxiety and depression scale: An updated literature review. J Psychosomat Res 2002;52(2):69-77. (PMID:11832252).

14. Balhara $Y$, Verma R, Sharma S, Mathur S. A study of predictors of anxiety and depression among stroke patient-caregivers. J Mid-Life Health 2012;3(1):31-35. (PMID: 22923977)

15. Epstein-Lubow G, Beevers C, Bishop D, Miller I. Family functioning is associated with depressive symptoms in caregivers of acute stroke survivors. Arch Phys Med Rehabil. 2009;90(6):947-55. (PMID: 19480870).

16. Han B, Haley W. Family caregiving for patients with stroke: review and analysis. Stroke. 1999;30(7):147885. (PMID: 10390326).
17. Berg A, Palomaki H, Lonnqvist J, Lehtihalmes M, Kaste M. Depression among caregivers of stroke survivors. Stroke 2005;36(3):639-43. (PMID: 15677575).

18. Greenwood N, Mackenzie A, Cloud G, Wilson N. Informal carers of stroke survivors--factors influencing carers: a systematic review of quantitative studies. Disabil Rehabil 2008;30(18):1329-49. (PMID:19230230).

19. Low J, Payne S, Roderick P. The impact of stroke on informal carers: a literature review. Soc Sci Med. 1999;49(6):711-25. (PMID:10459884).

20. McPherson C, Wilson K, Chyurlia L, Leclerc C. The caregiving relationship and quality of life among partners of stroke survivors: A cross-sectional study. Health Qual Life Out 2011;9:29. (PMID:21554723).

21. Jonsson A, Lindgren I, Hallstrom B, Norrving $B$, Lindgren A. Determinants of quality of life in stroke survivors and their informal caregivers. Stroke 2005;36(4):803-8. (PMID:15761203).

22. Ogunlana M, Dada O, Oyewo O, Odole A, Ogunsan M. Quality of life and burden of informal caregivers of stroke survivors. Hong Kong Physiother J 2014;32(1):612. doi:10.1016/j.hkpj.2013.11.003

23. Morimoto T, Schreiner A, Asano H. Caregiver burden and health-related quality of life among Japanese stroke caregivers. Age Ageing. 2003;32(2):218-23. (PMID:12615568).

24. Pinedo S, SanMartin V, Zaldibar B, et al. Quality of life of stroke patients and their caregivers. Int J Phys Med Rehabil 2017;5:387. doi:10.4172/2329-9096.1000387 